\title{
Endovascular Treatment of Brachiocephalic and Subclavian Arterial Disease
}

\author{
Yasutaka Baba $^{1}$, Sadao Hayashi ${ }^{1}$, Hiroyuki Yamamoto ${ }^{2}$, Yutaka Imoto ${ }^{2}$, Masayuki Nakajo ${ }^{1}$ \\ ${ }^{1}$ Department of Radiology, Graduate School of Medical and Dental Sciences, \\ Kagoshima University, Kagoshima City, Japan \\ ${ }^{2}$ Department of Cardiovascular Surgery, Graduate School of Medical and Dental Sciences, \\ Kagoshima University, Kagoshima City, Japan \\ Email: yasutaka@m3.kufm.kagoshima-u.ac.jp
}

Received November 9, 2012; revised December 8, 2012; accepted December 15, 2012

\begin{abstract}
Objectives: To review our experience of stentgraft deployment for vascular aneurysm or pseudoaneurysm of the brachiocephalic or subclavian artery. Methods: Participants comprised 7 patients (4 men, 3 women; mean age, 61 years; range, 47 - 76 years) who underwent endovascular repair of brachiocephalic or subclavian arterial vascular lesions between July 2001 and November 2008. Causes of vascular lesions were: traffic accident, $n=4$; infection, $n=2$; and post-irradiation state of esophageal cancer, $\mathrm{n}=1$. Safety, technical success, and clinical follow-up were evaluated. Results: Stentgraft deployment was successful in all cases. No complications related to stent fracture were encountered during follow-up (up to 2308 days). One male patient with esophageal cancer died of rebleeding from the tracheostomy hole 13 days after treatment with size mismatch between the stentgraft and brachiocephalic artery. Conclusion: Stentgraft deployment represents acceptable treatment for the injured brachiocephalic artery or proximal side of the subclavian artery.
\end{abstract}

Keywords: Stentgraft; Brachiocephalic Artery; Subclavian Artery; Pseudoaneurysm

\section{Introduction}

The brachiocephalic and subclavian arteries are infrequently injured as a result of blunt or penetrating trauma, stab wounds, or iatrogenic trauma [1]. These conditions are associated with very high morbidity and mortality rates, because of the non-feasibility of surgery and the high risk of cerebrovascular disorders [2-7].

Endovascular treatment with stentgraft has recently been widely performed for vascular pseudoaneurysm, achieving high clinical success [8-21]. However, to the best of our knowledge, endovascular treatment with stentgrafting has not been summarized for pseudoaneurysm of the brachiocephalic artery or the proximal portion of the subclavian artery. This is probably due to mismatches in stent sizes for complicated configurations of brachiocephalic and proximal subclavian arteries.

We present our results for treatment using endovascular stentgraft deployment for aneurysm or pseudoaneurysm of the brachiocephalic artery and proximal portion of the subclavian artery.

\section{Methods}

Between July 2001 to November 2008, a total of 7 patients (4 men, 3 women) underwent endovascular repair of injured brachiocephalic and subclavian arteries and were thus included in this study. Mean age at the time of treatment was 66 years (range, 49 - 76 years). Causes of arterial lesions were as follows: motor vehicle trauma, $\mathrm{n}=4$; infection, $\mathrm{n}=2$; and post-irradiation state of esophageal cancer, $\mathrm{n}=1$. Sites of arterial injury are shown in Table 1. A patient selection criterion was that surgical alternatives had been discussed, with explanation of reasons for the unfeasibility of surgery.

The procedure was performed in an angiography suite $(n=1)$ or operation room $(n=6)$ with or without general anesthesia. Both angiographic systems were single-plane. Intravenous heparin and prophylactic antibiotic administration were performed routinely before stentgraft deployment and continued $\geq 3$ days. Arterial access was gained via the axillary $(n=3)$, carotid $(n=1)$ or femoral $(n=3)$ artery. Stentgrafts were introduced via a 9- or 10-Fr sheath. The stentgraft used included 2 bare stents with expanded polytetrafluoroethylene (ePTFE), and 5 Niti-S ComVi stentgrafts (Taewoong Medical, Seoul, South Korea). Measurements of diameter were made on precalibrated computer-generated digital-subtraction angiography images. Proximal stentgraft diameter was oversized $1-1.5 \mathrm{~mm}$ and the stentgraft extended beyond the lesion by $\geq 1 \mathrm{~cm}$ at each end.

Medical records were obtained to evaluate results of therapeutic follow-up from the time of endovascular 
treatment. Evaluation included stent or stentgraft patency, presence of hemostasis, and complications related to deployment of the stent or stentgraft.

\section{Results}

Stentgraft deployment was successful in all cases (Tables 1 and 2). Thrombosis or shrinkage of pseudoaneurysmal sacs was achieved in 6 cases (85\%) within 1 week after treatment (Figure 1). In 1 patient with esophageal cancer (Case 4; Figure 2), rebleeding from the tracheostomy hole occurred 13 days after treatment and he died of this bleeding. In other 6 patients (85\%), thrombosis of the aneurysmal sac or hemostasis was maintained during follow-up (range, 90 - 1094 days). In cases of blunt injury of the brachiocephalic artery (such as Case 5 in this series), deployment of a stentgraft is hazardous at the bifurcation between the carotid and subclavian arteries, due to the potential for obstruction of the carotid artery or brain embolism. We deployed the stentgraft between the carotid and brachiocephalic arteries to maintain blood flow to the brain. Following this procedure, coil embolization of the right subclavian artery was performed. Hemostasis was achieved later. Despite embolization of the right subclavian artery, blood flow to the right arm was compensated via retrograde flow from the vertebral artery. We performed a 4-vessel study before this procedure, but did not consider using a balloon occlusion test of the subclavian artery due to the risk of traumatic injury to the brachiocephalic artery. During follow-up, this patient did not complain of symptoms associated with complications such as subclavian steal syndrome.

In a patient with right subclavian artery injury and right-sided massive hemothorax (Case 6), the stentgraft covered the injury site. However, hemothorax with anemia was unresolved after deflating the thoracostomy tube. Thoracoscopy was then performed and arterial bleeding was noticed from small branches of the subclavian artery. Hemostasis was achieved after coagulation with an argon laser. In patients with infected pseudoaneurysm (Cases 3

Table 1. Patients characteristics.

\begin{tabular}{ccccc}
\hline No. & $\begin{array}{c}\text { Age/ } \\
\text { Gender }\end{array}$ & Cause & Injured artery & Stent \\
\hline 1 & $49 / \mathrm{M}$ & MVT & BCA & Handmade \\
2 & $76 / \mathrm{F}$ & MVT & left SA & Niti-S ComVi \\
3 & $67 / \mathrm{M}$ & Infection & right SA & Handmade \\
4 & $65 / \mathrm{M}$ & Esophageal Cancer & BCA & Niti-S ComVi \\
5 & $55 / \mathrm{F}$ & MVT & BCA & Niti-S ComVi \\
6 & $47 / \mathrm{M}$ & MVT & right SA & Niti-S ComVi \\
7 & $72 / \mathrm{F}$ & Infection & right SA & Niti-S ComVi \\
\hline
\end{tabular}

Note MVT: motor vehicle trauma; BCA: brachiocephalic artery; SA: subclavian artery. and 7; Figure 3), surgical bypass was performed first. Because the postoperative course was considered to be poor and highly sensitive to antibiotic therapy from aspirated pus in both patients, endovascular treatment with antibiotic therapy was attempted.

\section{Discussion}

Subclavian artery injury can be life-threatening [1-22].

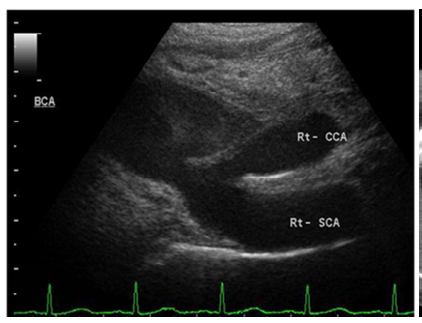

(a)

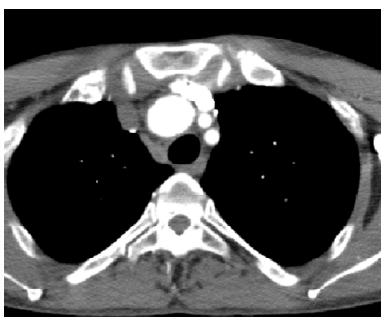

(b) (c)

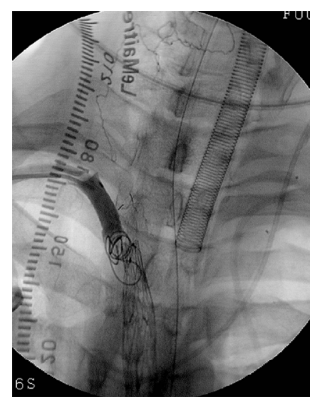

(f)

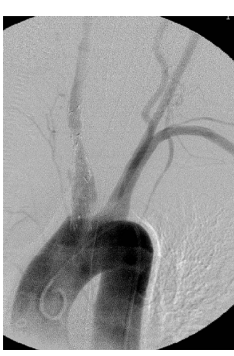

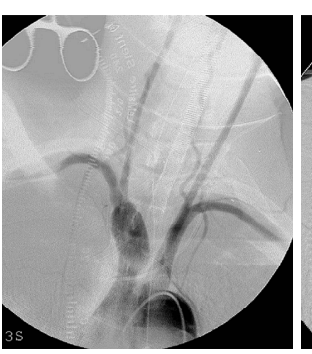

(d)

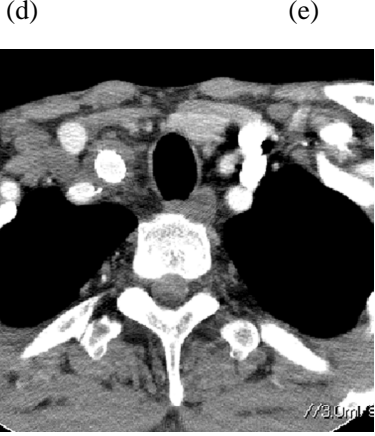

(g)
Figure 1. A 49-year-old man with injury of the brachiocephalic artery in a motor vehicle accident. (a) Ultrasonography demonstrates aneurysmal dilatation of the brachiocephalic artery (BCA). Rt-CCA, right common carotid artery; Rt-SCA, right subclavian artery; (b) Contrast-enhanced computed tomography (CT) revealing aneurysmal dilatation of the brachiocephalic artery; (c) Aortography showing aneurysmal dilatation of the brachiocephalic artery; (d) Aortography immediately after deployment of the stentgraft from the brachiocephalic artery to right common carotid artery, showing aneurysmal dilatation of the brachiocephalic artery via perigraft leakage; (e) Subclavian arteriography via the right brachial artery access, showing residual aneurysmal sac; (f) After coil embolization of the right subclavian artery, flush arteriography shows no visualization of any residual aneurysmal sac; (g) Contrast-enhanced CT showing no aneurysmal dilatation of the brachiocephalic artery. 
Table 2. Outcome.

\begin{tabular}{cccc}
\hline No. & Age/Gender & Hemostasis or not & Follow-up \\
\hline 1 & $49 / \mathrm{M}$ & Hemostasis & Lost follow-up \\
2 & $76 / \mathrm{F}$ & Hemostasis & Lost follow-up \\
3 & $67 / \mathrm{M}$ & Hemostasis & Thrombosed aneurysmal sac at 2308 days follow-up \\
4 & $65 / \mathrm{M}$ & Not hemostasis & Dead after 13 days follow-up \\
5 & $55 / \mathrm{F}$ & Hemostasis & Thrombosed aneurysmal sac at 1227days follow-up \\
6 & $47 / \mathrm{M}$ & Hemostasis & Thrombosed aneurysmal sac at 3 months follow-up \\
7 & $72 / \mathrm{F}$ & Hemostasis & Thrombosed aneurysmal sac at 3 months follow-up \\
\hline
\end{tabular}

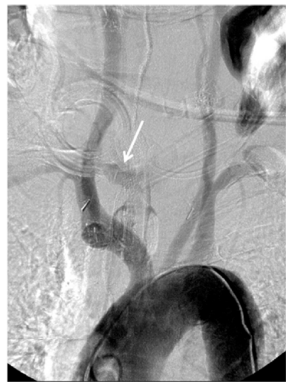

(a)

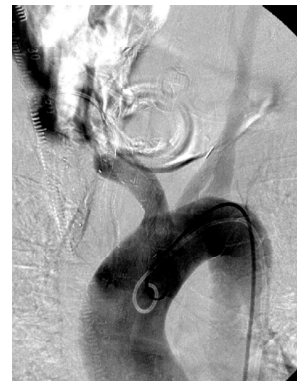

(b)
Figure 2. A 65-year-old man with esophageal cancer and bleeding via tracheostomy tube. (a) Aortography shows extravasation around the tracheostomy tube after deflating balloon lumen; (b) After deployment of stentgrafts, aortography shows the gap between stentgraft and brachiocephalic artery.

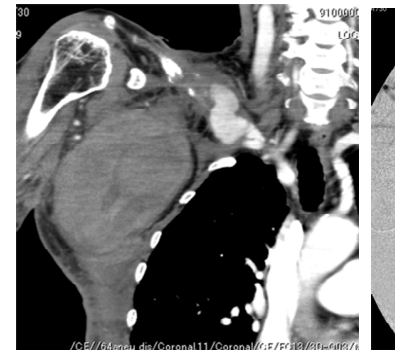

(a)

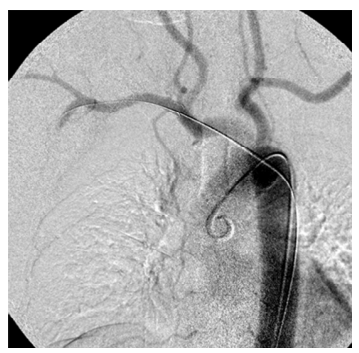

(c)

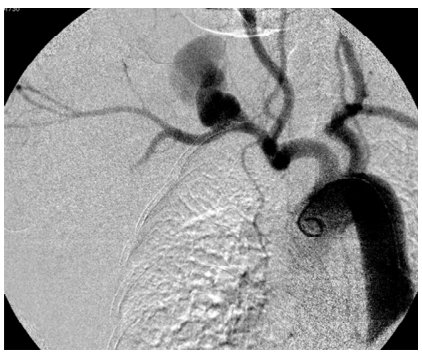

(b)

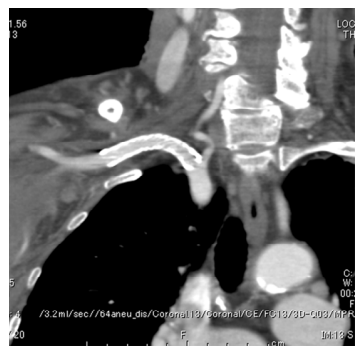

(d)
Figure 3. A 72-year-old-woman with infectious right subclavian pseudoaneurysm. (a) CT showing massive hematoma and pseudoaneurysm (arrow); (b) Aortography showing extravasation of contrast medium from the right subclavian artery; (c) Aortography after stentgraft deployment, showing no extravasation of contrast medium; (d) CT showing stentgraft of the right subclavian artery.
The prehospital mortality rate with subclavian trauma has been estimated as approximately 75\% [22]. Surgical repair is considered the first-line treatment for this condition. However, mortality rates during and after surgical treatment are not low, with reported postsurgical mortality rates ranging from $5 \%$ to $30 \%[2,23,24]$.

Stentgraft deployment for subclavian artery injury is feasible because of the low morbidity and mortality rates [10,12,15,16,19-21,25,26]. Becker et al. reported the first case, involving a 43-year-old man who underwent deployment of a balloon-expandable metallic stent for left subclavian injury [9], while du Toit et al. [13] reported that stentgraft treatment for subclavian artery injury resulted in high clinical success rates and low complication rates. However, stentgraft deployment in the peripheral portion of the subclavian artery has the potential risk of damage to the stentgraft from compression of the clavicle and rib [27]. In addition, du Toit et al. [13] reported stentgraft stenosis (20\%) and occlusion of the subclavian artery (12\%) after stentgraft deployment during 48 months of follow-up [13].

However, the clinical results of stentgraft deployment for brachiocephalic or proximal subclavian artery injuries have not been well documented. Reports of vascular injury in this region treated using endovascular treatment have been limited to case reports [8,11,14,17,28-32].

In a series of trachea-innominate artery fistula, overinflation of expandable metallic stentgrafts resulted in exposure of the metallic stent inside the tracheal lumen [30, 33]. In that report, the authors advocated deployment of stentgrafts in the bracheocephalic region only as a temporary procedure, to be followed by surgical treatment including aortosubclavian bypass [33].

\section{Conclusion}

Stentgraft deployment offers a feasible and acceptable treatment for injury to the brachiocephalic artery or proximal side of the subclavian artery.

\section{REFERENCES}

[1] D. Demetriades, D. Theodorou, E. Cornwell, T. V. Berne, 
J. Asensio, et al., "Evaluation of Penetrating Injuries of the Neck: Prospective Study of 223 Patients,” World Journal of Surgery, Vol. 21, No. 1, 1997, pp. 41-48. doi:10.1007/s002689900191

[2] D. Demetriades, S. Chahwan, H. Gomez, R. Peng, G. Velmahos, et al., "Penetrating Injuries to the Subclavian and Axillary Vessels," Journal of the American College of Surgeons, Vol. 188, No. 3, 1999, pp. 290-295. doi:10.1016/S1072-7515(98)00289-0

[3] V. Kalakuntla, V. Patel, A. Tagoe and W. Weaver, "SixYear Experience with Management of Subclavian Artery Injuries,” The American Journal of Surgery, Vol. 66, No. 10, 2000, pp. 927-930.

[4] M. S. Abouljoud, F. N. Obeid, H. M. Horst, V. J. Sorensen, J. J. Fath, et al., "Arterial Injuries of the Thoracic Outlet: A Ten-Year Experience,” The American Journal of Surgery, Vol. 59, No. 9, 1993, pp. 590-595.

[5] M. Bladergroen, R. Brockman, G. Luna, T. Kohler and K. Johansen, "A Twelve-Year Survey of Cervicothoracic Vascular Injuries,” The American Journal of Surgery, Vol. 157, No. 5, 1989, pp. 483-486. doi:10.1016/0002-9610(89)90640-5

[6] R. H. Johnston Jr., M. J. Wall Jr. and K. L. Mattox, "Innominate Artery Trauma: A Thirty-Year Experience,” Journal of Vascular Surgery, Vol. 17, No. 1, 1993, pp. 134140. doi:10.1016/0741-5214(93)90017-G

[7] J. O. Fulton, M. K. De Groot and U. O. von Oppell, "Stab Wounds of the Innominate Artery," The Annals of Thoracic Surgery, Vol. 61, No. 3, 1996, pp. 851-853. doi:10.1016/0003-4975(95)01154-4

[8] B. M. Axisa, I. M. Loftus, G. Fishwick, T. Spyt and P. R. Bell, "Endovascular Repair of an Innominate Artery False Aneurysm Following Blunt Trauma,” Journal of Endovascular Therapy, Vol. 7, No. 3, 2000, pp. 245-250. doi:10.1583/1545-1550(2000)007<0245:EROAIA >2.3.C $\underline{\mathrm{O} ; 2}$

[9] G. J. Becker, J. F. Benenati, G. Zemel, D. S. Sallee, C. A. Suarez, et al., "Percutaneous Placement of a BalloonExpandable Intraluminal Graft for Life-Threatening Subclavian Arterial Hemorrhage," Journal of Vascular and Interventional Radiology, Vol. 2, No. 2, 1991, pp. 225-229. doi:10.1016/S1051-0443(91)72286-0

[10] H. A. Bukhari, R. Saadia and B. W. Hardy, "Urgent Endovascular Stenting of Subclavian Artery Pseudoaneurysm Caused by Seatbelt Injury," Canadian Journal of Surgery, Vol. 50, No. 4, 2007, pp. 303-304.

[11] T. A. Chandler, G. Fishwick and P. R. Bell, "Endovascular Repair of a Traumatic Innominate Artery Aneurysm,” European Journal of Vascular and Endovascular Surgery, Vol. 18, No. 1, 1999, pp. 80-82. doi:10.1053/ejvs.1999.0871

[12] J. S. Danetz, A. D. Cassano, M. C. Stoner, R. R. Ivatury and M. M. Levy, "Feasibility of Endovascular Repair in Penetrating Axillosubclavian Injuries: A Retrospective Review,” Journal of Vascular Surgery, Vol. 41, No. 2, 2005, pp. 246-254. doi:10.1016/j.jvs.2004.11.026

[13] D. F. du Toit, A. V. Lambrechts, H. Stark and B. L. Warren, "Long-Term Results of Stent Graft Treatment of Subclavian Artery Injuries: Management of Choice for
Stable Patients?” Journal of Vascular Surgery, Vol. 47, No. 4, 2008, pp. 739-743. doi:10.1016/j.jvs.2007.11.009

[14] D. F. du Toit, W. Odendaal, A. Lambrechts and B. L. Warren, "Surgical and Endovascular Management of Penetrating Innominate Artery Injuries,” European Journal of Vascular and Endovascular Surgery, Vol. 36, No. 1, 2008, pp. 56-62. doi:10.1016/j.ejvs.2008.01.024

[15] D. F. du Toit, D. C. Strauss, M. Blaszczyk, R. de Villiers and B. L. Warren, "Endovascular Treatment of Penetrating Thoracic Outlet Arterial Injuries,” European Journal of Vascular and Endovascular Surgery, Vol. 19, No. 5, 2000, pp. 489-495. doi:10.1053/ejvs.1999.1050

[16] K. Kasirajan, B. Matteson, J. M. Marek and M. Langsfeld, "Covered Stents for True Subclavian Aneurysms in Patients with Degenerative Connective Tissue Disorders," Journal of Endovascular Therapy, Vol. 10, No. 3, 2003, pp. 647-652.

doi:10.1583/1545-1550(2003)010<0647:CSFTSA > 2.0.C $\mathrm{O} ; 2$

[17] E. J. Miles, A. Blake, W. Thompson, W. G. Jones and E. L. Dunn, "Endovascular Repair of Acute Innominate Artery Injury Due to Blunt Trauma," The American Journal of Surgery, Vol. 69, No. 2, 2003, pp. 155-159.

[18] J. C. Parodi, C. Schonholz, L. M. Ferreira and J. Bergan, "Endovascular Stent-Graft Treatment of Traumatic Arterial Lesions,” Annals of Vascular Surgery, Vol. 13, No. 2, 1999, pp. 121-129. doi:10.1007/s100169900230

[19] A. V. Patel, M. L. Marin, F. J. Veith, A. Kerr and L. A. Sanchez, "Endovascular Graft Repair of Penetrating Subclavian Artery Injuries," Journal of Endovascular Surgery, Vol. 3, No. 4, 1996, pp. 382-388. doi:10.1583/1074-6218(1996)003<0382:EGROPS >2.0.C $\mathrm{O} ; 2$

[20] M. Schoder, M. Cejna, T. Holzenbein, G. Bischof, F. Lomoschitz, et al., "Elective and Emergent Endovascular Treatment of Subclavian Artery Aneurysms and Injuries," Journal of Endovascular Surgery, Vol. 10, No. 1, 2003, pp. 58-65. doi:10.1583/1545-1550(2003)010<0058:EAEETO>2.0.C $\underline{\mathrm{O} ; 2}$

[21] E. S. Xenos, M. Freeman, S. Stevens, D. Cassada, J. Pacanowski, et al., "Covered Stents for Injuries of Subclavian and Axillary Arteries," Journal of Vascular Surgery, Vol. 38, No. 3, 2003, pp. 451-454. doi:10.1016/S0741-5214(03)00553-6

[22] A. G. McKinley, A. T. Carrim and J. V. Robbs, "Management of Proximal Axillary and Subclavian Artery Injuries,” British Journal of Surgery, Vol. 87, No. 1, 2000, pp. 79-85. doi:10.1046/j.1365-2168.2000.01303.x

[23] N. M. Rich, R. W. Hobson, B. S. Jarstfer and T. M. Geer, "Subclavian Artery Trauma," The Journal of Trauma, Vol. 13, No. 6, 1973, pp. 485-496. doi:10.1097/00005373-197306000-00001

[24] S. M. George Jr., M. A. Croce, T. C. Fabian, E. C. Mangiante, K. A. Kudsk, et al., "Cervicothoracic Arterial Injuries: Recommendations for Diagnosis and Management," World Journal of Surgery, Vol. 15, No. 1, 1991, pp. 134-140. doi:10.1007/BF01658986

[25] D. F. du Toit, J. G. Leith, D. C. Strauss, M. Blaszczyk, J. 
de V. Odendaal, et al., "Endovascular Management of Traumatic Cervicothoracic Arteriovenous Fistula,” British Journal of Surgery, Vol. 90, No. 12, 2003, pp. 15161521. doi:10.1002/bjs.4343

[26] S. C. Wheeler, K. M. Zinn and T. W. Hughes, "Endovascular Covered Stent Repair of an Iatrogenic Subclavian Artery-to-Pulmonary Artery Fistula and Pseudoaneurysm,” Journal of Vascular and Interventional Radiology, Vol. 18, No. 6, 2007, pp. 775-779. doi:10.1016/j.jvir.2007.02.029

[27] L. H. Phipp, D. J. Scott, D. Kessel and I. Robertson, "Subclavian Stents and Stent-Grafts: Cause for Concern?” Journal of Endovascular Surgery, Vol. 6, No. 3, 1999, pp. 223-226. doi:10.1583/1074-6218(1999)006<0223:SSASCF $>2.0 . C$ $\underline{\mathrm{O} ; 2}$

[28] A. F. Lennox, D. R. Logan, R. C. Waugh and J. May, "Endovascular Management of an Innominate-Caval Fistula Secondary to Insertion of a Cardiac Pacemaker," Circulation, Vol. 102, 2000, pp. E124-125. doi:10.1161/01.CIR.102.19.e124

[29] L. P. Wall, A. Gasparis and E. Criado, "Endovascular Therapy for Tracheoinnominate Artery Fistula: A Temporizing Measure,” Annals of Vascular Surgery, Vol. 19, No. 1, 2005, pp. 99-102. doi:10.1007/s10016-004-0140-4
[30] C. Sessa, V. Costache, P. Porcu, F. Thony, D. Blin, et al., "Tracheoinnominate Artery Fistula: Combined Endovascular and Surgical Management by Emergency StentGraft Placement Followed by Cryopreserved Arterial Allograft Repair,” Annals of Vascular Surgery, Vol. 20, No. 6, 2006, pp. 731-735. doi:10.1007/S10016-006-9086-z

[31] W. Y. Szeto, R. M. Fairman, M. A. Acker, C. L. Skelly, J. G. Augoustides, et al., "Emergency Endovascular Deployment of Stent Graft in the Ascending Aorta for Contained Rupture of Innominate Artery Pseudoaneurysm in a Pediatric Patient,” The Annals of Thoracic Surgery, Vol. 81, No. 5, 2006, pp. 1872-1875. doi:10.1016/j.athoracsur.2005.07.046

[32] K. Takasaki, K. Enatsu, M. Nakayama, T. Uchida and H. Takahashi, “A Case with Tracheo-Innominate Artery Fistula. Successful Management of Endovascular Embolization of Innominate Artery,” Auris Nasus Larynx, Vol. 32, No. 2, 2005, pp. 195-198. doi:10.1016/j.anl.2004.11.002

[33] E. M. Marone, G. Esposito, A. Kahlberg, Y. Tshomba, C. Brioschi, et al., "Surgical Treatment of Tracheoinnominate Fistula after Stent-Graft Implantation,” The Journal of Thoracic and Cardiovascular Surgery, Vol. 133, No. 6, 2007, pp. 1641-1643. doi:10.1016/j.jtcvs.2006.12.063 